\title{
Delving into the details of postpneumonectomy prognosis
}

\author{
Tara R. Semenkovich, MD, MPHS
}

\footnotetext{
From the Division of Cardiothoracic Surgery, Department of Surgery, Washington University in St. Louis, St. Louis, Mo.

T.R.S. was supported by a Barnes-Jewish Hospital Foundation Grant, National Institutes of Health (NIH) Grant Number 2T32HL7776-21, and the Division of Cardiothoracic Surgery at Washington University in St. Louis. Disclosures: Author has nothing to disclose with regard to commercial support.

Received for publication Sept 6, 2018; accepted for publication Sept 6, 2018.

Address for reprints: Tara R. Semenkovich, MD, MPHS, Division of Cardiothoracic Surgery, Washington University in St. Louis, 660 S Euclid Ave, Campus Box 8234, St. Louis, MO 63110 (E-mail: semenkovicht@wudosis. wustl.edu).

J Thorac Cardiovasc Surg 2018;156:2366-7

$0022-5223 / \$ 36.00$

Copyright (c) 2018 Published by Elsevier Inc. on behalf of The American Association for Thoracic Surgery https://doi.org/10.1016/j.jtcvs.2018.09.019
}

Pneumonectomy carries a substantial risk of perioperative morbidity and mortality. Improving outcomes can be approached in 2 different ways: first, by identifying modifiable factors in perioperative patient management that impact morbidity, and, second, by identifying preoperatively available patient factors that allow better patient selection and appropriate counseling for patients who may be at very high risk. Advances in either approach will enhance the quality of care provided.

Previous studies have identified several aspects of intraoperative management that affect outcomes. Excessive intravenous fluid administration, ${ }^{1}$ blood transfusion, ${ }^{2}$ and longer anesthetic time ${ }^{3}$ have been associated with adverse outcomes. The intraoperative use of protective lung ventilation has been shown in randomized, controlled trials to decrease the risk of postoperative lung injury. ${ }^{4}$ Perioperative care measures such as these are worthwhile endeavors that can improve outcomes incrementally for all patients undergoing pneumonectomies.

Still, it remains important to understand which patients are at the highest risk of perioperative mortality in order to thoughtfully consider operative treatment in the first place. Although baseline lung function and predicted postoperative spirometry values are evidence-based critical components of the preoperative physiologic workup, ${ }^{5}$ the additional patient factors most predictive of postoperative morbidity are less well defined.

In this issue of The Journal of Thoracic and Cardiovascular Surgery, Blanc and colleagues ${ }^{6}$ present an in-depth analysis of risk factors of postpneumonectomy respiratory failure, the complication most strongly associated with in-hospital mortality. They studied a large and detailed institutional cohort, which allowed them to perform a multivariable analysis aimed at specifically identifying preoperative factors that should alter clinical decision making. Interestingly, they found that predicted postoperative forced expiratory volume in 1 second was not associated with acute respiratory failure, perhaps

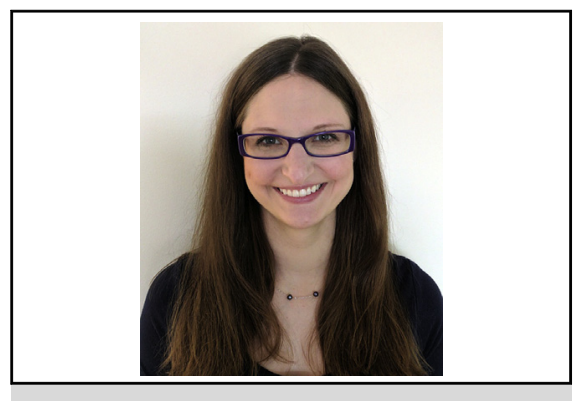

Tara R. Semenkovich, MD, MPHS

Central Message

Identifying patients at highest risk for postoperative respiratory failure to improve patient selection is one approach to reducing morbidity and mortality of pneumonectomy.

See Article page 2368.

suggesting that the rest of the preoperative workup effectively risk stratified patients on this measure. Alternatively, the effect of decreased postoperative lung function may have been captured by the significant variable of right-sided versus left-sided pneumonectomy, reflecting the lungs' differential contributions-roughly $55 \%$ from the right lung and $45 \%$ from the left lungto overall function. In addition, they found that Charlson Comorbidity Index, cardiovascular disease, and extended resection were associated with reintubation, confirming the importance of these variables noted in earlier series. $^{3,7,8}$ Although this study alone does not lay to rest the question of which additional patient factors are most important in risk assessment, nor does it allow development of a risk-prediction tool, it is a valuable contribution to the existing small body of literature.

Blanc and colleagues ${ }^{6}$ also confirmed the prognostic importance of reintubation for postoperative respiratory failure: 30-day mortality was $41.6 \%$ for reintubated patients versus $1.1 \%$ for nonreintubated patients. In addition, they present detailed postoperative data on both baseline characteristics and complications that were associated with acute respiratory failure and examine variables associated with survival in reintubated patients. Understanding which patients are likely to survive a serious pulmonary complication and which are likely to die further informs risk assessment. Although the small size of this subset of patients limits the number of factors that can be evaluated on multivariable analysis, consideration of the data from this viewpoint is novel 
and useful. Many factors were comparable between the groups of survivors and nonsurvivors, highlighting an area in which further research is needed.

\section{References}

1. Alam N, Park BJ, Wilton A, Seshan VE, Bains MS, Downey RJ, et al. Incidence and risk factors for lung injury after lung cancer resection. Ann Thorac Surg. 2007; 84:1085-91.

2. Blank RS, Hucklenbruch C, Gurka KK, Scalzo DC, Wang XQ, Jones DR, et al. Intraoperative factors and the risk of respiratory complications after pneumonectomy. Ann Thorac Surg. 2011;92:1188-94.

3. Algar FJ, Alvarez A, Salvatierra A, Baamonde C, Aranda JL, López-Pujol FJ. Predicting pulmonary complications after pneumonectomy for lung cancer. Eur J Cardiothoracic Surg. 2003;23:201-8.
4. Yang M, Ahn HJ, Kim K, Kim JA, Yi CA, Kim MJ, et al. Does a protective ventilation strategy reduce the risk of pulmonary complications after lung cancer surgery?: a randomized controlled trial. Chest. 2011;139:530-7.

5. Brunelli A, Kim AW, Berger KI, Addrizzo-Harris DJ. Physiologic evaluation of the patient with lung cancer being considered for resectional surgery: diagnosis and management of lung cancer, 3rd ed: American College of Chest Physicians evidence-based clinical practice guidelines. Chest. 2013;143(5 Suppl):e166S-90S.

6. Blanc K, Dechartres A, Zaimi R, Lefebvre A, Janet-Vendroux A, Fournel L, et al Patients experiencing early acute respiratory failure have high postoperative mortality after pneumonectomy. J Thorac Cardiovasc Surg. 2018;156:2368-76.

7. Bernard A, Deschamps C, Allen MS, Miller DL, Trastek VF, Jenkins GD, et al. Pneumonectomy for malignant disease: factors affecting early morbidity and mortality. J Thorac Cardiovasc Surg. 2001;121:1076-82.

8. Shapiro M, Swanson SJ, Wright CD, Chin C, Sheng S, Wisnivesky J, et al. Predictors of major morbidity and mortality after pneumonectomy utilizing the Society for Thoracic Surgeons general thoracic surgery database. Ann Thorac Surg. 2010;90:927-35. 